\title{
Coupled atmosphere ocean climate model simulations in the Mediterranean region: effect of a high-resolution marine model on cyclones and precipitation
}

\author{
A. Sanna ${ }^{1}$, P. Lionello ${ }^{1,2}$, and S. Gualdi ${ }^{1,3}$ \\ ${ }^{1} \mathrm{CMCC}$, viale Aldo Moro 44, 40127 Bologna, Italy \\ ${ }^{2}$ Unisalento, S.P. 6, Monteroni, 73100 Lecce, Italy \\ ${ }^{3}$ INGV, via Donato Creti 12, 40128 Bologna, Italy \\ Correspondence to: A. Sanna (antonella.sanna@cmcc.it)
}

Received: 6 November 2012 - Published in Nat. Hazards Earth Syst. Sci. Discuss.: Revised: 1 February 2013 - Accepted: 20 February 2013 - Published: 19 June 2013

\begin{abstract}
In this study we investigate the importance of an eddy-permitting Mediterranean Sea circulation model on the simulation of atmospheric cyclones and precipitation in a climate model. This is done by analyzing results of two fully coupled GCM (general circulation models) simulations, differing only for the presence/absence of an interactive marine module, at very high-resolution $\left(\sim 1 / 16^{\circ}\right)$, for the simulation of the 3-D circulation of the Mediterranean Sea. Cyclones are tracked by applying an objective Lagrangian algorithm to the MSLP (mean sea level pressure) field. On annual basis, we find a statistically significant difference in vast cyclogenesis regions (northern Adriatic, Sirte Gulf, Aegean Sea and southern Turkey) and in lifetime, giving evidence of the effect of both land-sea contrast and surface heat flux intensity and spatial distribution on cyclone characteristics. Moreover, annual mean convective precipitation changes significantly in the two model climatologies as a consequence of differences in both air-sea interaction strength and frequency of cyclogenesis in the two analyzed simulations.
\end{abstract}

\section{Introduction}

The Mediterranean region is characterized by complex orography and coastlines. Its peculiar latitudinal location, in a transitional area between tropical and mid-latitude variability and its complex geometry are important drivers for local phenomena characterizing its climate, such as lee cyclogenesis (Trigo et al., 2002), local winds of sustained speed such as Bora, Mistral, Etesian winds (Zecchetto and De Biasio, 2007), and deep-water formation (Mertens and Schott, 1998; MEDOC Group, 1970).

Global climate models have too coarse a resolution to correctly describe air-sea fluxes of heat and momentum over the region (Elguindi et al., 2009). Recent studies focused on the importance of the coupling with a high-resolution marine model. For instance, Somot et al. (2008) showed that the use of a regional coupled model over the EuroMediterranean region results in an amplification of the climatic signal with respect to analogous simulations performed with an atmosphere-only model. Going in the same direction, Artale et al. (2010), using the PROTEUS regional coupled model over Mediterranean area, produced more realistic simulations of SST (sea surface temperature), winds and, as a consequence, of air-sea fluxes. More recently, within the framework of the CIRCE EU-FP6 project, Gualdi et al. (2012) and Dubois et al. (2012) investigated the effect of high-resolution Mediterranean components within fully coupled atmosphere-ocean models on present climate and climate projection, using the IPCC scenario A1B (IPCC TAR, 2001), which shows that only high-resolution models permit a realistic simulation of the surface air-sea fluxes.

While the importance of the atmospheric forcing and its detailed representation (both temporal and spatial) on Mediterranean marine circulation (e.g., dense water formation and characteristics) have already been extensively investigated (Madec et al., 1991 and Artale et al., 2002), the opposite feedback is still an issue under debate. 
In the present study we examine a subset of the results of the CIRCE project, presented by Gualdi et al. (2012). We recall that the all the models participating in the CIRCE project are characterized by the presence of a very high resolution component for the simulation of the 3-D Mediterranean circulation. Specifically, the results of the CMCCMED model (Scoccimarro et al., 2011) for present climate are compared with those of a control simulation (CMCC$\mathrm{CM}$ ), carried out with the same model but switching off the coupling with the high-resolution Mediterranean component. This permits the investigation of both the effects of global atmospheric circulation on the Mediterranean Sea and vice versa.

In this study we specifically investigate the feedback on the atmospheric circulation due to the presence of the highresolution eddy-permitting marine module, focusing on the effects on cyclones and their characteristics.

Cyclogenesis in the Mediterranean region is primarily caused by orographic effects (Buzzi and Tibaldi, 1978). Nevertheless, latent heat release is also important for cyclogenesis intensification, especially when high SSTs destabilize air masses and favor the release of latent heat (Trigo et al., 2002). Such an effect seems to be quite important in the eastern Mediterranean region (Alpert and Ziv, 1989; Shay-El and Alpert, 1991). It results in an increase of the available energy and moisture for the atmospheric convection and consequently for precipitation.

Lebeaupin et al. (2006) highlighted that an SST increase induces systematically a CAPE (convective available potential energy) increase. Giordani and Caniaux (2001) have shown that the differential surface heating/moistening and thus the spatial variability of surface fluxes can be a significant source of ageostrophy, vertical velocity and vorticity for the atmosphere that plays a fundamental role in the cyclone development.

Our assumption is that an eddy-permitting model, realistically simulating the marine circulation, also permits a more realistic representation of SST structure, in terms of patterns, gradients and evolution. The SST field feedback on air-sea surface heat fluxes and lower atmospheric layer stability will in turn impact on cyclogenesis and cyclone characteristics, and eventually on mean atmospheric climate. In particular, a feedback on precipitation is expected. It is worth adding that Mediterranean cyclone characteristics, such as intensity or orographic forcing/interaction, would have benefited from a higher resolution than that of the atmospheric models used in this study. Unfortunately, dealing with GCMs the huge computational power needed to run at higher resolution was unaffordable. On the other hand, previous studies such as Flocas et al. (2010) demonstrate the capability of a dataset such as ERA40 (Uppala et al., 2005), even when downgraded to 2.5 degrees resolution, to reproduce Mediterranean cyclone climatology. Moreover, the observations available for comparison come from reanalysis projects, which have a maximum resolution of about $80 \mathrm{~km}$ (ERA-Interim, Berrisford et al., 2009), which is comparable to that of the atmospheric component of the analyzed GCMs.

Numerous previous studies examined the relationship between precipitation and cyclones over the Mediterranean Basin. Lionello et al. (2003) analyzed the effect of coupling among atmospheric and ocean circulation by implementing a coupled atmosphere ocean model in the Mediterranean region. In their findings SST was increased by the coupling, and precipitation decreased during the considered set of events. On the other hand, Jansa et al. (2001) investigated the relationship between heavy convective episodes on western Mediterranean and cyclones, finding that a large portion of convective rainfall is ascribable to MSLP depressions. Reale and Lionello (2012) have investigated the link between cyclones originating within the Mediterranean region and the associated precipitation events, finding that precipitation over eastern coasts is mostly related to cyclones generated inside the Mediterranean and that an important fraction of intense precipitation events in the southern areas are produced by cyclones originating over northern Africa. Lionello and Giorgi (2007) found that the reduction of cyclone activity inside the Mediterranean region in future scenarios is responsible for the lower precipitation at the southern and eastern Mediterranean coast in a regional climate model simulation.

This article is organized as follows: Section 1 is devoted to the description of the two models and the data used for validation. The algorithm used to track cyclones and the statistics used to characterize their features are also described. Section 2 analyzes the effects of the high-resolution marine model on the sea surface temperature (Sect. 2a), on the Mediterranean cyclone climatology (Sect. 2b) and on the precipitation field (Sect. 2c). Section 3 discusses main results, and Sect. 4 presents the conclusions.

\section{Data and methods}

The models employed in this work are two GCMs: the CMCC-MED and the CMCC-CM. Both models are an evolution of the INGV-SXG (Gualdi et al., 2008; Bellucci et al., 2008) and the ECHAM-OPA-LIM (Fogli et al., 2009; Vichi et al., 2011) models.

The atmospheric model component is ECHAM5 (Roeckner et al., 2003), with a T159 horizontal resolution, corresponding to a Gaussian grid of about $0.75^{\circ} \times 0.75^{\circ}$. This configuration has 31 hybrid sigma-pressure levels in the vertical and top at $10 \mathrm{hPa}$. A more detailed description of the ECHAM model performance can be found in Roeckner et al. (2006).

The global ocean component is OPA 8.2 (Océan PArallélisé, Madec et al., 1998), in its ORCA2 global configuration. The horizontal resolution of $2^{\circ} \times 2^{\circ}$ presents a meridional refinement near the equator, where it approaches a minimum $0.5^{\circ}$ grid spacing. For more details about the ocean model and its performance, readers are referred to Madec et 
al. (1998; information also available online at http://www. lodyc.jussieu.fr/opa/).

Every $160 \mathrm{~min}$ (coupling frequency), time-averaged heat, mass, and momentum fluxes are provided to the ocean model by the atmospheric model. At the same time, SST and sea surface velocities are provided to the atmospheric model by the ocean model.

CMCC-MED differs from CMCC-CM for the additional presence of a very high resolution eddy-permitting marine module (MFS, Oddo et al., 2009) for the Mediterranean Sea, in order to better represent the dynamical processes that characterize this region. This model has a $1 / 16^{\circ}$ horizontal resolution and 71 levels along the vertical. In the coupling with MFS, only SST is provided to the atmospheric component. It is worth noticing that the improved information due to the very high resolution of MFS is partly deteriorated in the coupling procedure by averaging the SST over the coupling frequency time and by interpolating the field to the coarse atmospheric model. On the other hand, Dubois et al. (2012), examining the performances of CIRCE models in terms of surface heat and water budgets over Mediterranean Sea, showed that the presence of an underlying marine model, which realistically simulates the small-scale spatial structures over the Mediterranean, is still beneficial in terms of the air-sea interactions.

Both model integrations start from an equilibrium state, obtained after a spin-up period of $200 \mathrm{yr}$ (with greenhouse gasses (GHGs) concentrations, corresponding to 1950 s conditions), which is an order of time commonly considered sufficient to reach a state of statistical equilibrium in GCMs (Trenberth, 1992). Then they have been integrated for the period 1951-2010 using prescribed GHGs according to observations until 2000 and to A1B SRES scenario from 2001 to 2010. In this study we focus our analysis on the period 1981-2010.

Model results are verified against ERA-Interim for MSLP and other atmospheric fields, HadISST for SST (Rayner et al., 2003), SOC datasets (Josey et al., 1996) for sea surface heat fluxes and CMAP observations (Xie and Arkin, 1996) for precipitation. Results are tested for statistical significance with a $t$ test (Von Storch and Zwiers, 1999) at $95 \%$ significance level, where normal distribution is involved (namely for mean climatological fields), and with a non-parametric Kolmogorov-Smirnov test (Von Storch and Zwiers, 1999) at $90 \%$ significance level, where cyclone distributions are analyzed.

The method used to identify and track Mediterranean cyclones relies on an objective algorithm with Lagrangian approach. Basically, all tracking algorithms for extratropical cyclones are characterized by two steps: cyclone identification and tracking. Some methods use MSLP (Pettersen, 1956; Gulev et al., 2001; Maheras et al., 2001; Campins et al., 2011) or geopotential height at $1000 \mathrm{hPa}$ (Alpert et al., 1990; Trigo et al., 1999), others use relative vorticity at $850 \mathrm{hPa}$ (Sinclair, 1997; Flocas et al., 2001) or the Laplacian of sea level pressure (Simmonds and Murray, 1999; Simmonds and Key, 2000). In any case, Mediterranean cyclone climatology presents very distinctive features, which arise clearly, independent of the specific algorithm applied.

The tracking method applied in the present study is based on the search for MSLP minima, at time interval of $6 \mathrm{~h}$. The algorithm is based on a nearest-neighbor search procedure: a cyclone trajectory is determined by computing the distance to cyclones detected in previous chart. For further details on the technique used, the reader is referred to Lionello et al. (2002). This tracking procedure is a rather simple one and presents some limitations. MSLP is a field strongly influenced by large-scale features and, because of this, smallscale fast-moving systems can be missed. Moreover, it is an extrapolated field, possibly very sensitive to the extrapolation procedure, especially over steep orography regions. On the other hand, a plethora of previous climatologies are based upon MSLP, and this offers a useful basis for comparison. Hoskins and Hodges (2002), investigating a series of tracking methods for extratropical cyclones in the Northern Hemisphere, found that MSLP and relative vorticity at $850 \mathrm{hPa}$ produced similar results. Nevertheless, it is worth mentioning that our tracking methodology, neither establishing a threshold for minimum cyclone intensity nor for terrain elevation (see Pinto et al., 2006) is subject to counting all lee depressions forming on Genoa sea (which in most of the cases do not originate proper extratropical cyclones) and thermal lows as proper cyclogenesis events. The algorithm used in this study is applied to both model results for the period 1981-2010 and to ERA-Interim (same period). Results are examined in terms of cyclogenesis density and usual cyclone feature statistics such as lifetime, maximum deepening rate, depth, and MSLP at minimum.

\section{Main effects of the Mediterranean eddy-permitting model}

\subsection{Effect on SST climatology}

We analyze the accuracy of the SST in the two GCM simulations (CMCC-MED and CMCC-CM) by comparing its distribution and annual cycle with the HadISST climatology.

Figure 1a shows the difference between the control run (CMCC-CM) and the observed climatology for the period 1981-2008 (HadISST being available only until 2008). The control run underestimates the observed SST almost everywhere, with values ranging from $-1{ }^{\circ} \mathrm{C}$ at the southeastern and western coasts to $-3^{\circ} \mathrm{C}$ in the central and northern parts of the basin (Ionian Sea, Aegean Sea, Tyrrhenian and Northern Adriatic seas). Figure 1b shows the difference between CMCC-MED and HadISST. The eddy-permitting model, with its higher horizontal resolution, more vertical levels and more accurate surface process parameterizations than CMCC-CM, allows a better representation of the 

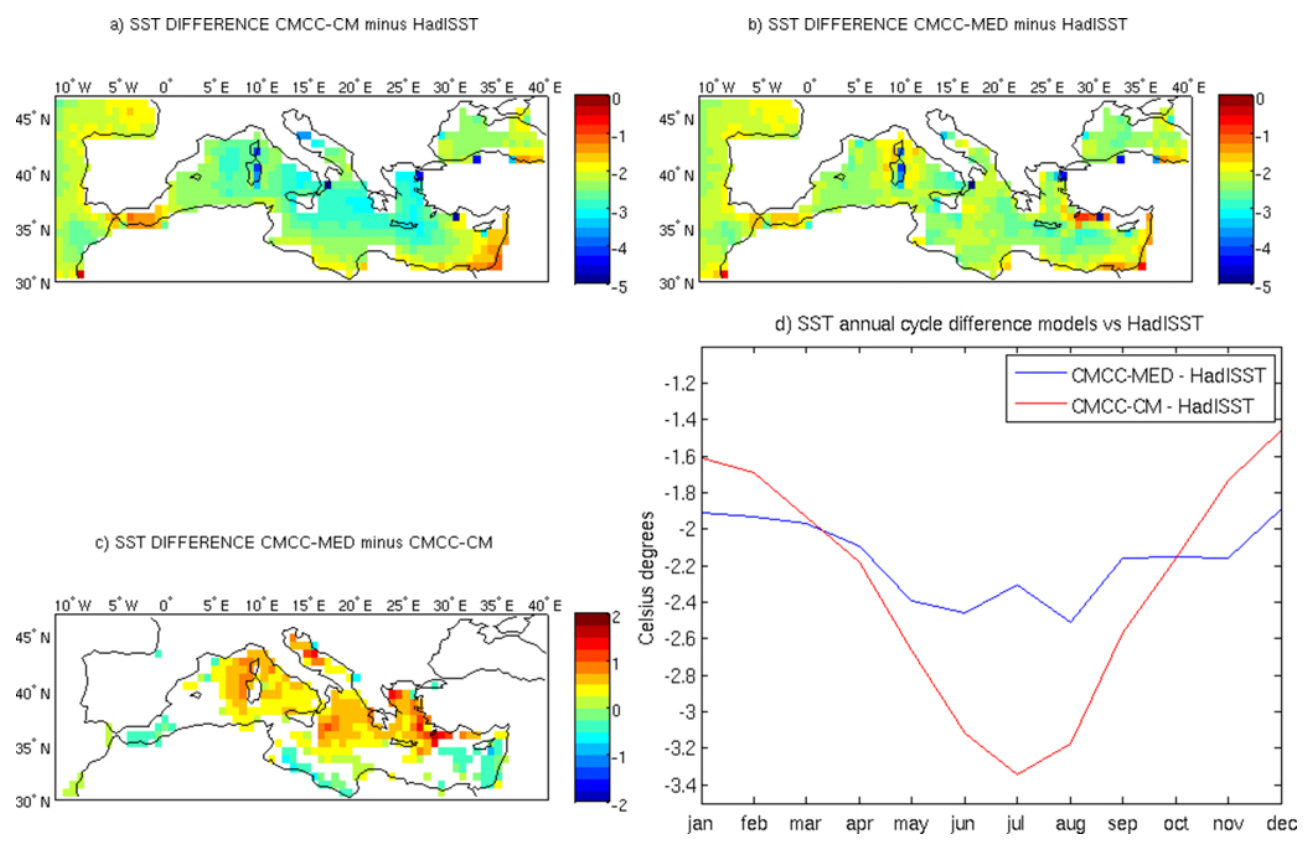

Fig. 1. Average SST bias in CMCC-CM (panel a) and in CMCC-MED (panel b) for the 1981-2008 period. Negative values indicate that both model simulations are colder than observations. Panel (c) shows the average SST difference between CMCC-MED and CMCC-CM (positive values in areas where CMCC-MED is warmer that CMCC-CM). Colored areas denote differences that are statistically significant at the $95 \%$ confidence level (a $t$ test was used).Values according to color bars. Panel (d) shows the SST annual cycle difference between HadISST and CMCC-MED (blue curve) and CMCC-CM (red curve).

Mediterranean dynamics, with a positive feedback on SST simulation. The cold bias of CMCC-CM is clearly reduced by CMCC-MED everywhere, especially in the central and northern part of the basin, but it is still around $2{ }^{\circ} \mathrm{C}$. On the other hand, Dubois et al. (2012) found that all CIRCE models simulate SSTs (and air temperatures) that are cooler than the observations. Such a shortcoming encompasses several reasons, ranging from radiative forcings to the marine albedo, but the problem is still under debate and a clear understanding of its reasons is still missing.

Figure 1c shows the difference between the two simulated SSTs and evidence that the eddy-permitting circulation model produces substantially higher SST in the northern and central part of the basin, and marginally lower SST (almost everywhere within $.25^{\circ} \mathrm{C}$ ) offshore from the southern coast of the basin and in the Levantine Sea.

Figure 1d shows the annual cycle of the basin-averaged SST difference between CMCC-CM (red curve), CMCCMED (blue curve) and HadISST. The negative bias of CMCC-CM presents a clear seasonality, with a stronger underestimation of SST during summer. CMCC-MED reduces the cold bias and improves the annual cycle especially during summer, but it has a small detrimental effect in the winter season. In any case, the amplitude of the annual cycle of the bias with respect to observations is reduced from approximately $2{ }^{\circ} \mathrm{C}$ in CMCC-CM to $.5^{\circ} \mathrm{C}$ in the CMCC-MED.
The improvement of CMCC-MED with respect to CMCC$\mathrm{CM}$ is expected to have a beneficial effect on all the phenomena affected by the SST annual cycle, such as cyclogenesis, latent heat flux and precipitation.

\subsection{Effect on cyclones and their characteristics}

This subsection analyzes the effect of the eddy-permitting ocean circulation component on frequency of cyclogenesis, cyclone lifetime and maximum deepening rate.

The monthly frequency distribution of cyclogenesis events has been computed as the number of the MSLP minimum first detections in each $2.5^{\circ} \times 2.5^{\circ}$ lat.-long. cell of the Mediterranean region, following Trigo et al. (1999). Differently from Trigo et al. (1999), and analogously as Campins et al. (2011), we include in our analysis also cyclones lasting less than $24 \mathrm{~h}$. The analysis has been applied to both model results and ERA-Interim.

Results (shown in Fig. 2a on annual basis for the control run) are in agreement with previous findings (Trigo et al., 1999; Maheras et al., 2001; Campins et al., 2011). The main cyclogenetic regions (Gulf of Genoa, Cyprus, Atlas Mountains, Black Sea and Balearic Sea) are correctly represented and also the seasonality of cyclogenesis is realistically reproduced. Consistent with observations, Genoa cyclones are present throughout the year, with a peak in the winter season, whereas Saharan and Cyprus cyclones mainly are found during spring and summer months. Compared to the recent 
a) $\mathrm{CMCC}-\mathrm{CM}$

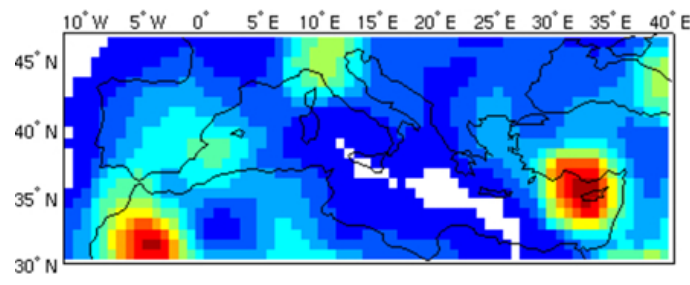

c) CMCC-CM - ERAI

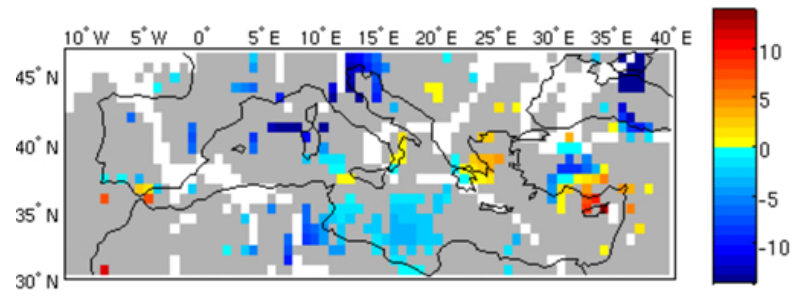

b)CMCC-MED - CMCC-CM

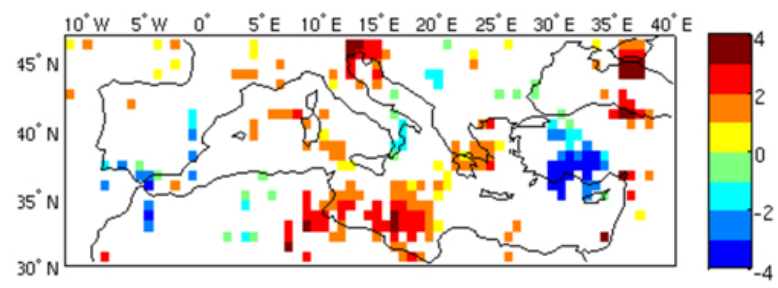

d) CMCC-MED - ERAI

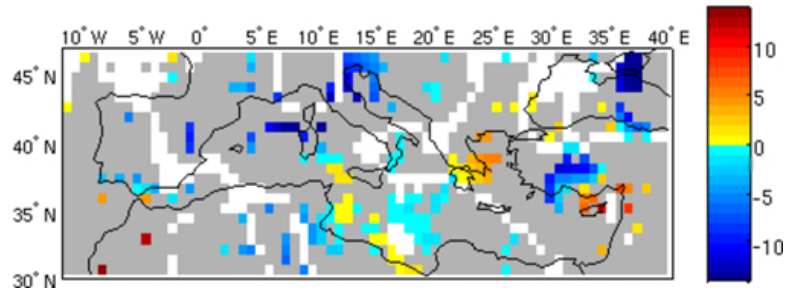

Fig. 2. Panel (a): annual mean number of cyclogenesis events, tracked in CMCC-CM climatology. Panel (b): difference (CMCC-MED minus CMCC-CM) in mean number of cyclogenesis events per year (reference period 1981-2010). Only statistically significant differences (KS test non-parametric, $90 \%$ ) are shaded. Panel (c): as panel (a), but for differences between CMCC-CM and ERA-Interim. Panel (d): as panel (a), but for differences between CMCC-MED and ERA-Interim. In panels (c) and (d), differences are shaded in grey, where the difference between CMCC_MED and CMCC-CM is not significant (see panel a).

climatology by Campins et al. 2011 (namely their Table 2 and Fig. 2), our methodology overestimates the number of cyclogenesis over Cyprus and over the Atlas Mountains. This is most likely due to the fact that their procedure removes very weak centers adding a criterion based on a pressure gradient threshold, while in our case all low centers are accounted for. However, our analysis deals with a different period (namely 1981-2010 versus 1957-2002).

Compared to ERA-Interim (Fig. 2c), the control run presents a tendency to underestimate the number of events, which is in line with the results found in previous modeling studies (e.g., Raible et al., 2010; Pinto et al., 2006; Bengtsson et al., 2006) and is likely to be due to model resolution lower than the real orography.

A comparison between CMCC-MED and the control run results shows that cyclogenesis on annual basis is affected by the resolution of the marine component. Figure $2 b$ shows that CMCC-MED, with respect to CMCC-CM, increases the frequency of cyclogenesis over the sea around Sardinia and to its southeast, over the northern Adriatic and Austria, over a large portion of the Mediterranean Sea north of the Gulf of Sirte and over Greece, while decreases it at the southern coast of Turkey. Colored areas denote differences that are statistically significant on annual basis. Figures $2 \mathrm{c}$ and $\mathrm{d}$ show the difference in annual cyclogenesis between ERAInterim and the two models. In order to focus on the beneficial or detrimental effect of the high-resolution model, the areas where the difference between the two model simulations is not significant (blank areas in panel a) are masked (grey) in Fig. 2c and d. Both models tend to underestimate the observed annual mean cyclogenesis. CMCC-MED is more accurate than CMCC-CM over the Gulf of Sirte, the Ionian Sea, the northern Adriatic (where the presence of the eddypermitting model increases the cyclogenesis frequency and partially compensates the underestimate of CMCC-CM), and worse than CMCC-CM over Greece and the Levantine Basin.

Figure $3 \mathrm{a}$ shows the difference in yearly mean lifetime between the two models. The CMCC-MED simulation has more (almost $2 \%$ ) short-lived events (that is, cyclones lasting less than $30 \mathrm{~h}$ ) than the CMCC-CM simulation. An examination of the spatial distribution of these short-lived events (not shown) indicates that some are located over the sea and are probably spurious local minima due to the shortcoming of the methodology applied. Others originate along the coasts and are likely to be due to low-level baroclinicity, induced by thermal land-sea contrasts, which are likely to be enhanced by the higher resolution and better coastal line definition of CMCC-MED.

CMCC-MED has more (almost $6 \%)$ long-lived events ( 5 days, Fig. 3a) than CMCC-CM, probably related to warmer SST in the CMCC-MED simulation because of the stronger sea surface fluxes associated. It is worth noticing that the overall resulting number of such long-lived events is about 3 cyclones $\mathrm{yr}^{-1}$. This number can be apparently small, being the Mediterranean one of the regions of the world with the highest frequency of extratropical cyclogenesis. On the other hand, a cyclone lasting 5.5 days is a very rare event in the Mediterranean, where cyclones typically last 2-3 days (see e.g., Trigo et al., 1999 and Campins et al., 2011). 



Fig. 3. Cyclone statistics. Panel (a): lifetime difference between CMCC-MED and CMCC-CM. Panel (b): maximum deepening rate (hPa/6h) in both models for the spring season. Panel (c): as panel (b), but for September. Black dots mark statistically significant differences.

Maximum deepening rate is shown in Figs. $3 b$ and c, for the spring season and September, respectively; that is, the only periods where these statistics significantly differ between the two models. In particular, spring maximum deepening rates in CMCC-MED are always higher than in CMCC-CM, giving indication of a higher number of cyclones in that season in the CMCC-MED configuration. On the other hand, September (Fig. 3c) shows a different distribution in CMCC-MED with respect to CMCC-CM, with an increased number of cyclones with maximum deepening rate around $7-8 \mathrm{hPa} 6 \mathrm{hr}^{-1}$.

\subsection{Effect on precipitation}

In general, the effect of the eddy-permitting marine model on mean atmospheric variables is modest, with small and nonsignificant differences in the $500 \mathrm{hPa}$ geopotential height, MSLP and wind fields (not shown), with the exception of convective precipitation, where an increase of up to $50 \%$ in the mean annual value with respect to CMCC_CM is found in some locations (Fig. 4a).

Convective precipitation exhibits large and statistically significant differences in five regions: the northern Adriatic, the Gulf of Sirte and Ionian Sea (hereafter SIPREC area), the region around Sardinia, the Aegean Sea and the eastern Levatine Sea (Fig. 4a). All changes are positive, with the exception of the eastern Levantine Sea. The overall patterns of the difference in convective precipitation and of latent heat flux are very similar (Fig. 4b). In particular, areas with stronger/weaker flux in CMCC-MED than in the control run correspond to areas with more/less intense convec- tive precipitation. Figure $4 \mathrm{c}$ and d show the difference between the observed latent heat fluxes (SOC climatology) and the two models (CMCC-CM and CMCC-MED). The validation is done over the period 1981-2005, with the observations being available only until 2005 . The comparison with the observations shows that the presence of the high-resolution marine module reduces the bias with the climatological observed values all over the western and central Mediterranean basins, while the simulated latent heat flux over the Levantine Basin seems to be almost unchanged, if not partly degraded, in CMCC-MED configuration.

In order to explore the link between changes in cyclogenesis intensity and precipitation, we focused on the Sirte Gulf (namely $10^{\circ} \mathrm{W}-22^{\circ} \mathrm{E}, 31^{\circ} \mathrm{N}-37^{\circ} \mathrm{N}$, hereafter the SICYC area), where the largest effect of the eddy-permitting model on cyclogenesis occurs and the bias of the control simulation with respect to observations is reduced. For each convective episode in the $30 \mathrm{yr}$ simulated by CMCC-MED and CMCC$\mathrm{CM}$, occurring in the SIPREC area, we looked for the nearest cyclone within a radius of about $600 \mathrm{~km}$ and, following backward its trajectory, we found the associated cyclogenetic area. The choice of the radius value is made following Jansa et al. (2001). Results are shown in Fig. 5a as the mean annual difference (CMCC-MED minus CMCC-CM) in cyclogenesis density. Increased precipitation over SIPREC is related to differences in cyclogenesis over two main areas: the northwestern Mediterranean and the central Mediterranean (including the SICYC area). On the one hand, cyclogenesis differences in the northwestern Mediterranean are not significant. Therefore, the increased precipitation triggered by these cyclones cannot be explained in terms of higher cyclogenesis 
a) CONVECTIVE PRECIPITATION

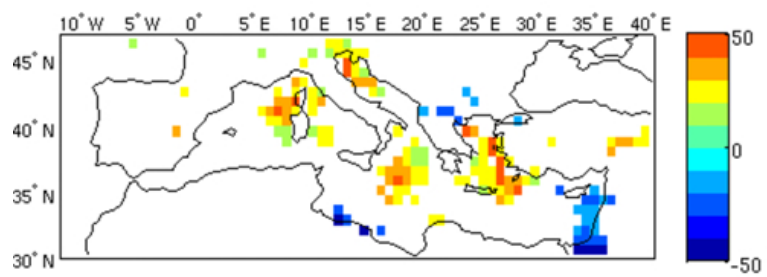

c) LH DIFFERENCE SOC - CMCC-CMED

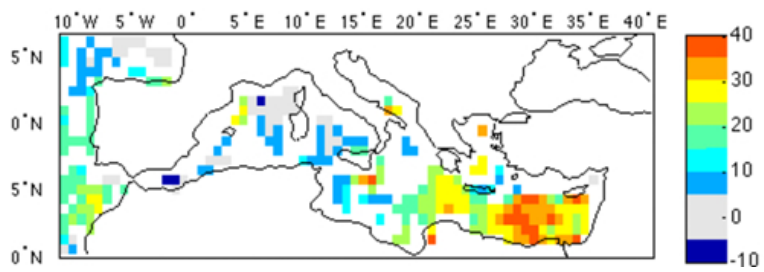

b) LATENT HEAT FLUX

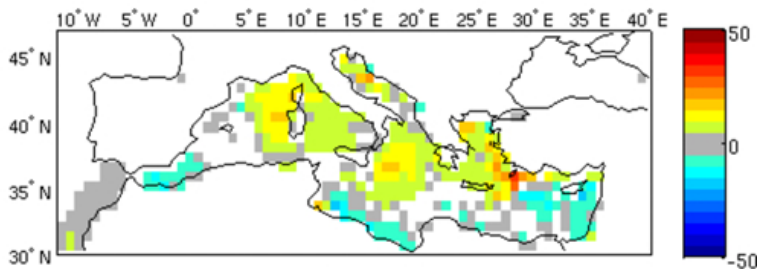

d) LH DIFFERENCE SOC - CMCC-CM

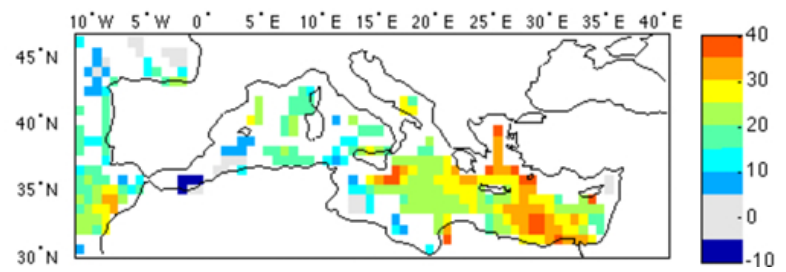

Fig. 4. Climatological differences. Panel (a): convective precipitation. Values are expressed in percentages (CMCC-MED-CMCCCM)/CMCC-CM. Panel (b): surface latent heat flux (Watt $/ \mathrm{m}^{2}$ ). Panel (c) and (d) show differences between SOC latent heat fluxes and model results (CMCC-CM and CMCC-MED respectively), over the period 1981-2005. Isolines are according to colorbars. Only statistically significant differences ( $t$ test $95 \%$ ) are shaded.

a) cyclogenesis density difference

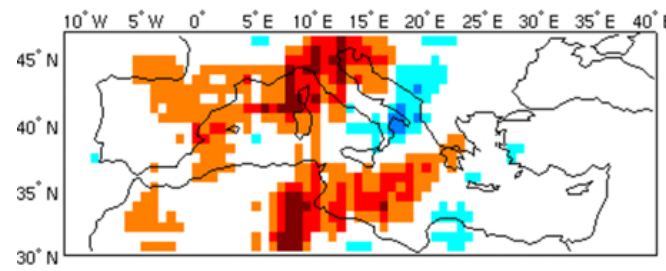

b) CMCC-MED track density SICYC area

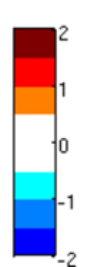

Fig. 5. Panel (a): annual differences (CMCC-MED-CMCC-CM) in cyclogenetic regions associated to precipitation over SIPREC area (defined in the text and shown in Fig. 4a). Panel (b): annual mean track density of cyclones originating from SICYC area (defined in the text) in CMCC-MED climatology. Only densities greater than $.5 \mathrm{yr}^{-1}$ (lower than $-.5 \mathrm{yr}^{-1}$ ) are shaded. Isolines according to colorbars.

density, and it is likely to be due to enhanced air-sea interactions in CMCC-MED (such as surface latent heat flux) over the SIPREC area. On the other hand, cyclogenesis in the SICYC area occurs more frequently in the CMCC-MED simulation than in the control simulation, which is consistent with the increase of precipitation. This result suggests that at least part of the increase of convective rainfall occurring over SIPREC area is caused by more frequent cyclogenesis in the SICYC area. In order to corroborate our reasoning, we computed the track density of cyclones originating in SICYC for CMCC-MED simulation (Fig. 5b), which is clearly consistent with precipitation over SIPREC area.

We finally verified the model performance at simulating the total precipitation field, comparing the two model climatologies with the observed CMAP dataset. Figure 6a shows the difference between the mean fields of the two models for the period 1981-2005; that is, where the observations are available. Differences are statistically significant only over small portion of the Mediterranean area, specifically over southern France and northern Italy, near Sardinia, over a part of the central basin, over the Aegean Sea and along the eastern coast of the basin. With the exception of the latter region, differences are always positive, indicating an increase of total precipitation up to $20 \%$. On the other hand, Fig. $6 \mathrm{~b}$ shows the difference between the observed total precipitation climatology and the control run (CMCC-CM), giving evidence of an overall underestimate. These results confirm that the effect of the eddy-permitting model is beneficial also on the precipitation field.

\section{Discussion of results}

As the Mediterranean cyclogenesis is primarily orographic, the main cyclogenetic areas (Gulf of Genoa, Cyprus, Atlas 
a) TOTPREC DIFFERENCE CMCC-MED - CMCC-CM

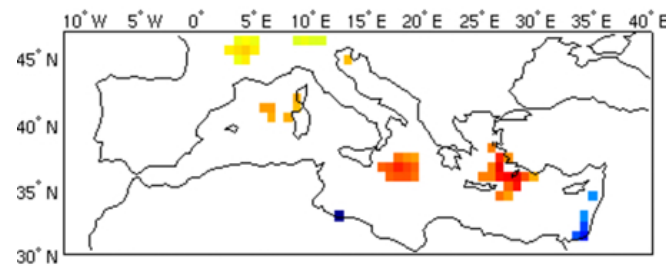

b) TOTPREC DIFFERENCE CMAP - CMCC-CM

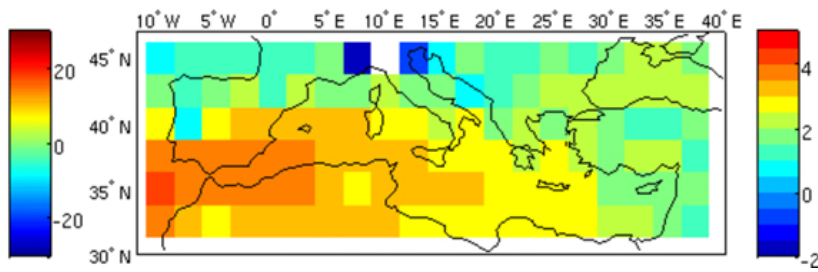

Fig. 6. Difference in mean total precipitation. Panel (a): difference between the two models. Values are expressed in percentages (CMCCMED-CMCC-CM)/CMCC-CM. Panel (b): CMAP - CMCC-CM total precipitation (1981-2005). Values are absolute differences in mm days ${ }^{-1}$. Isolines according to colorbars. Only statistically significant differences $(t$ test $95 \%)$ are shaded.

Mountains) are not affected by the introduction of the eddypermitting Mediterranean model. Nevertheless, stronger land/sea contrasts together with steeper SST gradients, due to better resolved coastal lines and marine circulation, are responsible for an increase in the mean number of cyclogenesis over large sectors of the basin (such as the SICYC area) where the orographic forcing is a less critical cyclogenetic factor. Here surface heat fluxes (basically latent heat), SST gradients and lower atmospheric instabilities can influence the capability of a model to reproduce the observed cyclogenesis.

Moreover, changes in marine representation have a clear effect on cyclone characteristics, such as lifetime and maximum deepening rate. In particular, while lifetime distribution is affected by the higher resolution of the Mediterranean model throughout the year, maximum deepening rate presents different behaviors. We found indications of an increased number of cyclones during spring, while a modification of the distribution is found in September. Both results are consistent with an intensification of heat fluxes, which are typical in those periods, because the thermal contrast between the lower atmospheric layers and the underlying sea reaches a maximum. Stronger latent and sensible heat, from a warmer underlying sea, favor destabilization of lower tropospheric maritime air, decreasing the static stability and leading to more favorable cyclonic conditions.

The link between the strength of air-sea fluxes and cyclonic activity has been previously found and discussed (e.g., Yao et al., 2008). For instance, surface heat fluxes can trigger diabatic instabilities, initiating small marine cyclones even in the absence of upper-level forcing (Mak, 1998). This destabilization mechanism is stronger in CMCC-MED than in CMCC-CM, probably due to stronger SST and heat fluxes gradients.

The mechanisms through which sea surface fluxes can lead to intensification of convection are illustrated by Miglietta et al. (2011). Investigating the effect of SST on a medicane (Mediterranean hurricane) by means of numerical simulations, they show that the sensible and latent heat fluxes from the sea surface are efficient mechanisms for convective destabilization. In particular, moistening the low levels, the heat fluxes favor the destabilization of the boundary layer, which facilitates the release of convection and allows continuous replenishment of the buoyant energy, favoring the maintenance of convection. Similarly, Jansa et al. (2001) found that a cyclonic center may contribute to low-level organization and intensification of low-level warm currents that feed and sustain convective rain.

Giordani and Caniaux (2001) investigated the effect of SST on open-ocean extratropical cyclogenesis, performing a set of sensitivity modeling experiments. In their findings, SST affects cyclone trajectory, its intensity and precipitation. Warm SSTs significantly enhance the convective activity and produce intense lows, which is consistent with our findings.

In this study we observed a clear feedback of a warmer SST on convective precipitation through the analysis of cyclone climatology. Our results indicate that the effect of cyclones on convective precipitation is due to either differences in genesis frequency within the basin area (such as in the SICYC area) or differences in cyclone features. Cyclone characteristics (lifetime and deepening rate) do change as a consequence of different SST and surface heat fluxes and their gradients. The climatological difference in latent heat fluxes between the two simulations (Fig. 4b) presents a pattern that is clearly related to that of convective precipitation. Where SST is warmer, stronger evaporation and latent heat release occur, both destabilizing the atmospheric boundary layer and providing the atmosphere with higher moisture content available for convection. On the other hand, colder SST (as in the Levantine Basin) induces weaker heat fluxes and reduced precipitation.

The overall effect on mean atmospheric climate is not relevant as far as dynamic fields such as geopotential height at various level (MSLP and $500 \mathrm{hPa}$ ) and surface winds are concerned. On the other hand, a statistically significant and relevant difference ( $20 \%$ order) affects the total precipitation, mainly attributable to its convective component (where differences reach $50 \%$ ). This result is corroborated by previous findings of Winschall et al. (2012), showing that Mediterranean evaporation accounts for most of the precipitable water that rains during Mediterranean convective events, while for large-scale precipitation events other sources of 
moisture (e.g., the Northeast Atlantic) are equally important. The observed effects on precipitation interest mainly sea regions, but can possibly affect the coasts of a large portion of the basin.

\section{Conclusions}

The importance of an eddy-permitting Mediterranean Sea circulation model on climate simulations has been investigated by considering its effect on atmospheric cyclone characteristics and precipitation. Two atmosphere-ocean general circulation model simulations of present climate conditions using coupled models differing only for the high/low resolution of the marine module have been compared.

Results show a strong and beneficial effect on the simulated SST and precipitation, which locally can reach $50 \%$, and a significant effect, which improves results in some areas, on cyclogenesis.

The SST simulated through the eddy-permitting model increases over the central and northern Mediterranean Sea, whereas it slightly decreases at the African coast, with respect to the control simulation. These results confirm that the use of an eddy-permitting model is important for the correct computation not only of mesoscale features, but also for the mean annual SST field and for its annual cycle.

The eddy-permitting model has a small, but generally positive effect on the frequency of cyclogenesis, which is consistent with the importance of intensity and small-scale structure of air-sea interaction.

The effect on precipitation is large and can locally produce an increase (up to a $50 \%$ ) of convective precipitation, with respect to the control simulation. This impact is mostly associated to locally increased convective activity, shown by a corresponding change of latent heat flux in the same areas, and with the same sign of the change of convective precipitation. However, a part of the precipitation increase is caused by more frequent cyclogenesis events in the areas where the cyclones that produced it were originated.

We are aware of previous studies ( $\mathrm{Li}, 2006)$ indicating that varying the SST over the Mediterranean Sea could initiate atmospheric teleconnections, which can influence remote regions of the world. We highlight that this study focuses specifically on the Mediterranean area and the effects over it.

Acknowledgements. We gratefully acknowledge the support of the Italian Ministry of Education, University and Research, and the Ministry for Environment, Land and Sea through the GEMINA project.

This work has been performed with the support of the CIRCE EU-FP6 Integrated Project under contract no. GOCE-036961.

Edited by: L. Bertotti

Reviewed by: F. Grazzini and two anonymous referees

\section{References}

Alpert, P. and Ziv, B.: The sharav cyclone - observations and some theoretical considerations, J. Geophys. Res., 94, 18495-18514, 1989.

Alpert, P., Neeman, B. U., and Shay-El, Y.: Climatological analysis of Mediterranean cyclones using ECMWF data, Tellus, 42A, 6577, doi:10.1034/j.1600-0870.1990.00007.x, 1990.

Artale, V., Iudicone, D., Santoleri, R., Rupolo, V., Marullo, S., and D'Ortenzio, F.: Role of surface fluxes in ocean general circulation models using satellite sea surface temperature: validation of and sensitivity to the forcing frequency of the Mediterranean thermohaline circulation, J. Geophys. Res., 107, 3120, doi:10.1029/2000JC000452, 2002.

Artale, V., Calmanti, S., Carillo, A., Dell'Aquila, A., Herrmann, M., Pisacane, G., Ruti, P. M., Sannino, G., Struglia1, M. V., Giorgi, F., Bi, X., Pal, J. S., Rauscher, S. and The PROTHEUS Group: An atmosphere-ocean regional climate model for the Mediterranean area: assessment of a present climate simulation, Clim. Dynam., 35, 721-740, 2010.

Bellucci, A., Gualdi, S., Scoccimarro, E., and Navarra, A.: NAO - ocean circulation interactions in a coupled general circulation model, Clim. Dynam., 31, 7-8, 759-777, doi:10.1007/s00382008-0408-4, 2008.

Bengtsson, L., Hodges, K. I., and Roeckner, E.: Storm tracks and climate change, J. Climate, 19, 3518-3543, 2006.

Berrisford, P., Dee, D., Fielding, K., Fuentes, M., Kallberg, P., Kobayashi, S., and Uppala, S.: The ERA Interim archive, Tech. Rep. ERA Rep. Series 1, ECMWF, 2009.

Buzzi, A. and Tibaldi, S.: Cyclogenesis in the lee of the Alps: A case study, Q. J. Roy. Meteor. Soc., 104, 271-287, doi:10.1002/qj.49710444004, 1978.

Campins, J., Genovès, A., Picornell, M. A., and Jansà, A.: Climatology of Mediterranean cyclondes using ERA-40 dataset, Int. J. Climatol., 31, 1596-1614, 2011.

Dubois, C., Somot, S., Calmanti, S., Carillo, A., Déqué, M., Dell'Aquila, A., Elizalde, A., Gualdi, S., Jacob, D., L'Hévéder, B., Li, L., Oddo, P., Sannino, G., Scoccimarro, E., and Sevault, F.: Future projections of the surface heat and water budgets of the Mediterranean Sea in an ensemble of coupled atmosphere-ocean regional climate models, Clim. Dynam., 39, 1859-1884, 2012.

Elguindi, N., Somot, S., Déqué, M., and Ludwig, W.: Climate change evolution of the hydrological balance of the Mediterranean, Black and Caspian Seas: impact of climate model resolution, Clim. Dynam., 36, 205-228, 2009.

Flocas, H., Maheras, P, Karacostas, T, Patrikas, I, and Anagnostopoulou, C.: A 40-year climatological study of relative vorticity distribution over the Mediterranean, Int. J. Climatol., 21, 17591778, doi:10.1002/joc.705, 2001.

Flocas, H., Simonds, I., Kouroutzoglou, J., Keay, K., Hatzaki, M., Bricolas, V., and Asimakopoulos, D.: On Cyclonic Tracks over the Eastern Mediterranean, J. Climate, 23, 5243-5257, 2010.

Fogli, P. G., Manzini, E., Vichi, M., Alessandri, A., Patara, L., Gualdi, S., Scoccimarro, E., Masina, S., and Navarra, A.: INGVCMCC Carbon (ICC): A Carbon Cycle Earth System Model, CMCC Technical Reports 61, 2009.

Giordani, H. and Caniaux, G.: Sensitivity of Cyclogenesis to Sea Surface Temperature in the Northwestern Atlantic, Mon. Wea. Rev., 129, 1273-1295, 2001. 
Gualdi, S., Scoccimarro, E., and Navarra, A.: Changes in Tropical Cyclone Activity due to Global Warming: Results from a HighResolution Coupled General Circulation Model, J. Climate, 21, 5204-5228, 2008.

Gualdi, S., Somot, S., Li, L., Artale, V., Adani, M., Bellucci, A., Braun, A., Calmanti, S., Carillo, A., Dell'Aquila, A., Déqué, M., Dubois, C., Elizalde, A., Harzallah, A., Jacob, D., L'Hévéder, B., May, W., Oddo, P., Ruti, P., Sanna, A., Sannino, G., Scoccimarro, E., Sevault, F., and Navarra, A.: The CIRCE simulations: a new set of regional climate change projections performed with a realistic representation of the Mediterranean Sea, BAMS, 94, 65-81, 2012.

Gulev, S., Zolina, O., and Grigoriev, S.: Extratropical cyclone variability in the Northern Hemisphere winter from the NCEP/NCAR reanalysis data, Clim. Dynam., 17, 795-809, 2001.

Hoskins, B. J. and Hodges, K. I.: New perspectives on the northern hemisphere winter storm tracks, J. Atmos. Sci., 59, 1041-1061, 2002.

IPCC TAR (WG1): Houghton, J. T., Ding, Y., Griggs, D. J., Noguer, M., van der Linden, P. J., Dai, X., Maskell, K., and Johnson, C. A.: Climate Change 2001: The Scientific Basis, Contribution of Working Group I to the Third Assessment Report of the Intergovernmental Panel on Climate Change, Cambridge University Press, ISBN 0-521-80767-0 (pb: 0-521-01495-6), 2001.

Jansa, A., Genoves, A., Picornell, M. A., Campins, J., Riosalido, R. and Carretero, O.: Western Mediterranean cyclones and heavy rain. Part2: Statistical approach, Meteorol. Appl., 8, 43-56, 2001.

Josey, S. A., Kent, E. C., Oakley, D., and Taylor, P. K.: A new global air-sea heat and momentum flux climatology, International WOCE, Newsletter, 25, 3-5, 1996.

Lebeaupin, C., Ducrocq, V., and Giordani, H.: Sensitivity of torrential rain events to the sea surface temperature based on highresolution numerical forecasts, J. Geophys. Res., 111, D12, doi:10.1029/2005JD006541, 2006.

Li, L. Z. X.: Atmospheric GCM response to an idealized anomaly of the Mediterranean sea surface temperature, Clim. Dynam., 27, 543-552, 2006.

Lionello, P. and Giorgi, F.: Winter precipitation and cyclones in the Mediterranean region: future climate scenarios in a regional simulation, Adv. Geosci., 12, 153-158, doi:10.5194/adgeo-12-1532007, 2007.

Lionello, P., Dalan, F., and Elvini, E.: Cyclones in the Mediterranean region: the present and the doubled $\mathrm{CO}_{2}$ climate scenarios, Clim. Res., 22, 147-159, 2002.

Lionello, P., Martucci, G., and Zampieri, M.: Implementation of a coupled atmosphere-wave-ocean model in the Mediterranean Sea: sensitivity of the short time scale evolution to the air-sea coupling mechanisms, The Global Atmos. Ocean Syst., 9, 6595, 2003.

Madec, G., Chartier, M., Delecluse, P., and Crepon, M.: A 3dimensional numerical study of deep-water formation in the northwestern mediterranean-sea, J. Phys. Ocean., 21, 13491371, 1991.

Madec, G., Delecluse, P., Imbard, M., and Levy, C.: OPA 8.1 Ocean General Circulation Model reference manual, Internal Rep. 11, Inst. Pierre-Simon Laplace, Paris, France, 1998.

Maheras, P., Flocas, H., Patrikas, I., and Anagnostopoulou, C.: A 40 year objective climatology of surface cyclones in the Mediter- ranean region: spatial and temporal distribution, Int. J. Climatol., 21, 109-130, doi:10.1002/joc.599, 2001.

Mak, M.: Influence of surface sensible heat flux on incipient marine cyclogenesis, J. Atmos. Sci., 55, 820-834, 1998.

MEDOC Group: Observation of formation of deep water in the Mediterranean Sea, 1969, Nature, 227, 1037-1040, 1970.

Mertens, C. and Schott, F.: Interannual Variability of DeepWater Formation in the Northwestern Mediterranean, J. Phys. Oceanogr., 28, 1410-1424, 1998.

Miglietta, M. M., Moscatello, A., Conte, D., Mannarini, G., Lacorata, G., and Rotunno, R.: Numerical analysis of a Mediterranean "hurricane" over south-eastern Italy: Sensitivity experiments to sea surface temperature, Atmos. Res., 101, 412-426, 2011.

Oddo, P., Adani, M., Pinardi, N., Fratianni, C., Tonani, M., and Pettenuzzo, D.: A nested Atlantic-Mediterranean Sea general circulation model for operational forecasting, Ocean Sci., 5, 461-473, doi:10.5194/os-5-461-2009, 2009.

Petterssen, S.: Weather Analysis and Forecasting, Volume I, Mac Graw Hill, New York, 1956.

Pinto, J. G., Spangehl, T., Ulbrich, U., and Speth, P.: Assessment of winter cyclone activity in a transient ECHAM4-OPYC3 GHG experiment, Meteorol. Z., 15, 279-291, 2006.

Raible, C. C., Ziv, B., Saaroni, H., and Wild, M.: Winter synopticscale variability over the Mediterranean Basin under future climate conditions as simulated by the ECHAM5, Clim. Dynam., 35, 473-488, 2010.

Rayner, N. A., Parker, D. E., Horton, E. B., Folland, C. K., Alexander, L. V., Rowell, D. P., Kent, E. C., and Kaplan, A.: Global analyses of sea surface temperature, sea ice, and night marine air temperature since the late nineteenth century, J. Geophys. Res., 108, 4407, doi:10.1029/2002JD002670, 2003.

Reale, M. and Lionello, P.: Synoptic climatology of winter intense precipitation events along the Mediterranean coasts, Nat. Hazards Earth Syst. Sci., in review, 2012.

Roebber, P. J.: The role of surface heat and moisture ?uxes associated with large-scale ocean current meanders in maritime cyclogenesis, Mon. Wea. Rev., 117, 1676-1694, 1989.

Roeckner, E., Bäuml, G., Bonaventura, L., Brokopf, R., Esch, M., Giorgetta, M., Hagemann, S., Kirchner, I., Kornblueh, L., Manzini, E., Rhodin, A., Schlese, U., Schulzweida, U., and Tompkins, A.: The atmospheric general circulation model ECHAM5. Part I: Model description, Rep. No. 349, Max-PlanckInstitut für Meteorologie, Hamburg, Germany, 127 pp., 2003.

Roeckner, E., Brokopf, R., Esch, M., Giorgetta, M., Hagemann, S., Kornblueh, L., Manzini, E., Schlese, U., and Schulzweida, U.: Sensitivity of simulated climate to horizontal and vertical resolution in the ECHAM5 atmosphere model, J. Climate, 19, 37713791, 2006.

Rudeva, I. and Gulev, S. K.: Composite Analysis of North Atlantic Extratropical Cyclones in NCEP-NCAR Reanalysis Data, Mon. Wea. Rev., 139, 1419-1446, 2011.

Scoccimarro, E., Gualdi, S., Bellucci, A., Sanna, A., Fogli, P. G., Manzini, E., Vichi, M., Oddo, P., and Navarra, A.: Effects of tropical cyclones on ocean heat transport in a high resolution coupled general circulationmodel, J. Climate, 24, 4368-4384, doi:10.1175/2011JCLI4104.1, 2011.

Shay-El, Y. and Alpert, P., : A diagnostic study of winter diabatic heating in the Mediterranean in relation to cyclone, Q. J. Roy. Meteor. Soc., 117, 715-747, 1991 
Simmonds, I. and Keay, K.: Variability of Southern Hemisphere extratropical cyclone behavior, 1958-97, J. Climate., 13, 550-561, 2000 .

Simmonds, I. and Murray, R.: Southern extratropical cyclone behavior in ECMWF analyses during the FROST special observing periods, Weather Forecast., 14, 878-891, 1999.

Sinclair, M.: Objective identification of cyclones and their circulation intensity and climatology, Weather Forecast., 12, 595-612, 1997.

Somot, S., Sevault, F., Dequé, M., and Crépon, M.: 21st century climate change scenario for the Mediterranean using a coupled atmosphere-ocean regional climate model, Glob. Planet Change, 63, 112-126, 2008.

Trenberth, E.: Climate System Modeling, Cambridge University Press, 788 pp., 1992.

Trigo, I., Davies, T., and Bigg, G.: Objective climatology of cyclones in the Mediterranean, Mon. Wea. Rev., 130, 1685-1696, 1999.

Trigo, I., Bigg, G., and Davies, T.: Climatology of cyclogenesis mechanisms in the Mediterranean, Mon. Wea. Rev., 130, 549$569,2002$.

Uppala, S. M., Kållberg, P. W., Simmons, A. J., Andrae, U., da Costa Bechtold, V., Fiorino, M., Gibson, J. K., Haseler, J., Hernandez, A., Kelly, G. A., Li, X., Onogi, K., Saarinen, S., Sokka, N., Allan, R. P., Andersson, E., Arpe, K., Balmaseda, M. A., Beljaars, A. C. M., van de Berg, L., Bidlot, J., Bormann, N., Caires, S., Chevallier, F., Dethof, A., Dragosavac, M., Fisher, M., Fuentes, M., Hagemann, S., Hólm, E., Hoskins, B. J., Isaksen, L., Janssen, P. A. E. M., Jenne, R., McNally, A. P., Mahfouf, J.-F., Morcrette, J.-J., Rayner, N. A., Saunders, R. W., Simon, P., Sterl, A., Trenberth, K. E., Untch, A., Vasiljevic, D., Viterbo, P., and Woollen, J.: The ERA-40 re-analysis, Q. J. R. Meteorol. Soc., 131, 2961-3012, doi:10.1256/qj.04.176, 2005.
Vichi, M., Manzini, E., Fogli, P. G., Alessandri, A., Patara, L., Masina, S., Gualdi, S., Scoccimarro, E., and Navarra, A.: Global and regional ocean carbon uptake and climate change: Sensitivity to an aggressive mitigation scenario, Clim. Dynam., 37, 19291947, 2011.

Von Storch, H. and Zwiers, F.: Statistical Analysis in Climate Research, Cambridge University Press, 494 pp., 1999.

Winschall, A., Pfahl, S., Sodemann, H., and Wernli, H.: Impact of North Atlantic evaporation hot spots on southern Alpine heavy precipitation events, Q. J. R. Meteorol. Soc., 138, 1245-1258, http://dx.doi.org/10.1002/qj.987, 2012.

Xie, P. and Arkin, P. A.: Analysis of global monthly precipitation using gauge observations, satellite estimates, and numerical model predictions, J. Climate, 9, 840-858, 1996.

Yao, Y., Perrie, W., Zhang, W., and Jiang, J.: Characteristics of atmosphere-ocean interactions along North Atlantic extratropical storm tracks, J. Geoph. Res., 113, doi:10.1029/2007JD008854, 2008.

Yuan, X., Patoux, J., and Li, C.: Satellite-based midlatitude cyclone statistics over the Southern Ocean: 2. Tracks and surface fluxes, J. Geophys. Res., 114, doi:10.1029/2008JD010874, 2009.

Zecchetto, S. and De Biasio, F.: Sea Surface Winds over the Mediterranean Basin from Satellite Data (2000-04): Meso and Local-Scale Features on Annual and Seasonal Time Scales, J. Appl. Meteor. Climatol., 46, 814-827, 2007. 